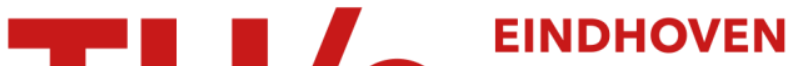 \\ UNIVERSITY OF \\ TECHNOLOGY
}

\section{Seeded emulsion polymerization of butadiene. 1 . The propagation rate coefficient}

\section{Citation for published version (APA):}

Verdurmen, E. M. F. J., Dohmen, E. H. M., Verstegen, J. M., Maxwell, I. A., German, A. L., \& Gilbert, R. G. (1993). Seeded emulsion polymerization of butadiene. 1. The propagation rate coefficient. Macromolecules, 26(2), 268-275. https://doi.org/10.1021/ma00054a004

DOI:

10.1021/ma00054a004

Document status and date:

Published: 01/01/1993

\section{Document Version:}

Publisher's PDF, also known as Version of Record (includes final page, issue and volume numbers)

\section{Please check the document version of this publication:}

- A submitted manuscript is the version of the article upon submission and before peer-review. There can be important differences between the submitted version and the official published version of record. People interested in the research are advised to contact the author for the final version of the publication, or visit the $\mathrm{DOI}$ to the publisher's website.

- The final author version and the galley proof are versions of the publication after peer review.

- The final published version features the final layout of the paper including the volume, issue and page numbers.

Link to publication

\section{General rights}

Copyright and moral rights for the publications made accessible in the public portal are retained by the authors and/or other copyright owners and it is a condition of accessing publications that users recognise and abide by the legal requirements associated with these rights.

- Users may download and print one copy of any publication from the public portal for the purpose of private study or research.

- You may not further distribute the material or use it for any profit-making activity or commercial gain

- You may freely distribute the URL identifying the publication in the public portal.

If the publication is distributed under the terms of Article 25fa of the Dutch Copyright Act, indicated by the "Taverne" license above, please follow below link for the End User Agreement:

www.tue.nl/taverne

Take down policy

If you believe that this document breaches copyright please contact us at:

openaccess@tue.nl

providing details and we will investigate your claim. 


\title{
Seeded Emulsion Polymerization of Butadiene. 1. The Propagation Rate Coefficient
}

\author{
Edwin M. Verdurmen, Erik H. Dohmen, John M. Verstegen, \\ Ian A. Maxwell, and Anton L. German* \\ Laboratory of Polymer Chemistry, Eindhoven University of Technology, P.O. Box 513, \\ 5600 MB Eindhoven, The Netherlands
}

\author{
Robert G. Gilbert
}

School of Chemistry, University of Sydney, Sydney, New South Wales 2006, Australia

Received April 6, 1992; Revised Manuscript Received September 6, 1992

\begin{abstract}
The kinetics of the emulsifier free seeded polymerization of butadiene at $60^{\circ} \mathrm{C}$ in SmithEwart interval III was investigated using sodium peroxodisulfate as initiator. The aim of this work was to measure the propagation rate coefficient $\left(k_{\mathrm{p}}\right)$ of butadiene at $60^{\circ} \mathrm{C}$ in emulsion polymerization. Modelindependent techniques to measure propagation rate coefficients like spatially intermitted polymerizations ${ }^{1-3}$ ("rotating sector" and "laser flash" photolysis) have not been used for butadiene so far since network formation prevents acquiring the necessary data from GPC. All experiments were conducted in the presence of tertdodecylmercaptan, as is usual in industrial practice. The fractional conversion was based on gravimetrically calibrated on-line densitometry and was found to be highly accurate. By analogy with the well-known Ugelstad plots, the product of the propagation rate coefficient $\left(k_{p}\right)$ and the average number of radicals per particle (n) versus seed latex particle diameter clearly shows Smith-Ewart case I and case II regimes. From a constancy in values of $k_{\mathrm{p}} n$ (case II regime) in this plot, a value for $k_{\mathrm{p}}$ could be calculated that was 3 times larger than the current literature value. It was found that negligible "thermal background initiation" is present in the butadiene system. Two linear regions in polymerization rate are observed in interval III. Model calculations are presented in excellent agreement with the experimental data. From these calculations a value of the rate coefficient for transfer to monomer, $k_{\mathrm{tr}}$, could be estimated.
\end{abstract}

\section{Introduction}

Despite the enormous volume of polybutadiene produced annually (use of SBR latex, and polybutadiene: 1378000 metric tons in 1990; ABS expected use 1.4 billion pounds in 19934) very little is reported in open literature on the emulsion polymerization of butadiene. Important papers on the subject have been published following the synthetic rubber program ${ }^{5}$ and by Morton et al. ${ }^{6-9}$ The latter reported work on cross-linking and kinetics assuming Smith-Ewart case II behavior. Wendler et al. ${ }^{10-13}$ reported on the emulsion polymerization of butadiene in the presence of large amounts of bis[(alkoxythio)carbonyl]disulfanes in order to prepare low molecular weight polymer. The results indicated a strong deviation from ideal Smith-Ewart case II behavior. Bhakuni ${ }^{14}$ concluded that the nature of the emulsifier influences the polymerization kinetics and also that network formation within the polymer has no influence on the saturation monomer solubility in the polymer. Radical desorption from the particles was proposed. These conclusions were confirmed and largely complemented by the work of Weerts et al..$^{15-21}$ These papers deal with a wide range of parameters such as: concentration and type of emulsifier (Rosin acid soap and SDS), electrolyte concentration, initiator concentration, degree of agitation, monomer to water ratio, and the tert-dodecylmercaptan concentration. On the basis of these experimental studies, important conclusions were made about the kinetics of the emulsion polymerization of butadiene.

The available literature value for the propagation rate coefficient $\left(k_{\mathrm{p}}\right)$ at $60^{\circ} \mathrm{C}$ reported by Morton et al..$^{8}$ is highly questionable inter alia because (1) the measurements were done on ab initio polymerizations at low temperatures $\left(0-30{ }^{\circ} \mathrm{C}\right.$; the value for $k_{\mathrm{p}}$ at $60^{\circ} \mathrm{C}$ is therefore an

\footnotetext{
* Author to whom correspondence should be addressed.
}

extrapolation), (2) particle sizing on latexes with broad particle size distributions was performed by the soap titration method, and (3) in the modeling of the data, Smith-Ewart case II kinetics were assumed.

Model-independent techniques to measure propagation rate coefficients like "spatially intermitted polymerizations"1-3 ("rotating sector" and "laser flash" photolysis) have not been used so far since the network formation of butadiene prevents acquisition of the necessary data from GPC. The aim of this paper is to evaluate the propagation rate coefficient of butadiene at $60^{\circ} \mathrm{C}$ by seeded emulsion polymerizations of butadiene in interval III, by an attempt to see a clear indication of case II $(\hat{n}=0.5)$ conditions. Knowing $n=0.5$ and from the observed rate and particle number, $k_{\mathrm{p}}$ can be found unambiguously.

\section{Experimental Section}

Butadiene (DSM Chemicals, Geleen, The Netherlands) was distilled directly from a 27-L storage vessel into a cooled stoel recipient. tert-Dodecylmercaptan (TDM), sodium peroxodisulfate (Fluka AG, Buchs, Switzerland), sodium dodecyl sulfate (p.a. Merck, Darmstadt, FRG), sodium carbonate (p.a. Merck, Darmstadt, FRG), and Aerosol MA 80 ( $80 \%$ solution in methanol; Cyanamid B.V., Rotterdam, The Netherlands) were all used without further purification. Water was doubly distilled and purged with nitrogen to remove oxygen.

Emulaion Polymerizations. The seeded emulsion polymerizations were carried out in a cylindrical stainless steel reactor $\left(1180 \mathrm{~cm}^{3}\right.$, diameter $=96 \mathrm{~mm}$, height $\left.=178 \mathrm{~mm}\right)$ fitted with four baffle plates located at $90^{\circ}$ intervals and a 12-blade turbine type impeller (diameter $=60 \mathrm{~mm}$, placed at a height of $1 / 3$ of the liquid level). The reactor was connected with a remote density meter (Anton Paar DMA 401, Graz, Austria) linked to a registration unit (Anton Paar DMA 60, Graz, Austria) and a computer. The reaction mixture was pumped with a piston-membrane pump (Orlita KG, MK 10, Giessen/Lahn, FRG) from the reactor into the density cell and back into the reactor. In this latex loop a thermocouple was installed to record the temperature of the passing liquid and thus to verify whether the latex flow was 
Table I

Standard Seeded Polymerization Rocipe and Description

\begin{tabular}{llc}
\multicolumn{1}{c}{ component } & \multicolumn{1}{c}{ recipe description } & recipe $(\mathrm{g})$ \\
\hline polybutadiene & $60 \%$ of max solid content & 97.5 \\
butadiene & $40 \%$ of max solid content & 65 \\
water & $90 \%$ of reaction mixture & 877.5 \\
sodium carbonate & $10^{-2}$ mol L-1 & 0.93 \\
sodium peroxodisulfate & $10^{-2}$ mol L-1 & 2.09 \\
tert-dodecylmercaptan & $1 \%$ on monomer & 0.65
\end{tabular}

continuous. The temperatures in the reactor and density meter were controlled by two separate thermostat baths (Lauda CS6 in combination with a R22 and $\mathrm{Pt}$ element) to $0.1^{\circ} \mathrm{C}$ accuracy. The recording of the thermocouple in the latex loop between the reactor and the density meter indicated a constant flow of latex through the density meter at a constant temperature after thermal equilibrium of the reaction mixture.

The recipe listed in Table $I$ is used for all polymerizations unless stated otherwise and is designed to minimize the gas cap in the reactor. The polybutadiene is added in the form of an emulsifier free seed latex. The preparation of this seed latex will be discussed in detail elsewhere. ${ }^{22}$ All the seed latexes are prepared under comparable process conditions. Note that no emulsifier is present in the polymerization recipe, except for perhaps small amounts of residual emulsifier on the seed latexes of 45 and $90 \mathrm{~nm}$ in diameter which were prepared using respectively Aerosol MA 80 and SDS.

The seed latexes used were dialyzed until low serum conductivity $\left(<20 \mu \mathrm{S} \mathrm{cm}^{-1}\right)$ to remove traces of initiator. Literature reports suggest that dialysis is an efficient but time-consuming method. ${ }^{23}$ Other methods are available ${ }^{24}$ but were found less effective in the present case. The reactor was charged with the following ingredients: seed latex, water, sodium carbonate, and TDM under a nitrogen atmosphere. The system was cleared of inert gases by flushing the gas cap with gaseous butadiene followed by evacuation. This procedure was repeated twice. The desired amount of butadiene was charged, and an emulsion was made by relatively mild agitation $(300 \mathrm{rpm})$. The monomer was allowed to swell the seed latex at $25^{\circ} \mathrm{C}$ for $24 \mathrm{~h}$. The time needed for complete swelling was verified by swelling a small amount of seed in a glass container in the same ratio of components as in the recipe, with inhibitor added to prevent polymerization. After $3 \mathrm{~h}$ no creaming occurred when agitation was stopped. It was concluded that a swelling time of $24 \mathrm{~h}$ was ample.

After swelling the initiator was added as a $50-\mathrm{mL}$ aqueous solution via a gas-tight syringe through a valve. The beginning of the polymerization was taken to be the time when the temperature was raised to $60^{\circ} \mathrm{C}$. After $20 \mathrm{~min}$ the swollen latex was allowed to flow through the density meter and the pump was started. During the rest of the polymerization, latex was continuously pumped through the density meter. After polymerization the reactor and density meter were thoroughly cleaned, pressurized, and checked for leaks. This was essential since butadiene is a liquified gas $\left(\approx 7 \mathrm{~atm}\right.$ at $\left.60^{\circ} \mathrm{C}\right)$ and therefore an enormous effect on the accuracy in conversion measurements is seen in the case of a slight leak.

The use of Anton Paar density meters in emulsion polymerization has been described elsewhere. ${ }^{25,26}$ The density meter was calibrated with six different liquids with density spanning the regime where density fluctuates during polymerization. The signal of the density meter varies linearly with density within the measured range. The calibration is incorporated in the computer program that records density data in 30-s intervals throughout the reaction. The polymerizations were performed in interval III (absence of monomer droplets) to enable densitometry to be accurately applicable. Due to the specific properties of butadiene (namely, the low viscosity and large density difference between monomer and water), creaming of butadiene is rapid. Consequently the absence of monomer droplets in interval III is desirable for the prevention of phase separation which would make densitometry untenable. On the other hand, the large density difference between monomer and polymer makes the butadiene system particularly suitable for monitoring the polymerization rate by densitometry. To calculate conversions from density data, one must either assume ideal mixing of monomer and polymer or calibrate the density readings. Weerts et al. ${ }^{16,21}$ reported that mixing of butadiene and polybutadiene is not ideal and that the mutual solubility of monomer and water is low enough to be ignored. Gravimetrical conversion data are used to calibrate density data by plotting gravimetrical conversion versus density at corresponding reaction times (see Figure 1). The correlation produced is used to transform the density data into conversion data $(x)$. Gravimetric samples were collected using a high-pressure proof syringe. From these samples the conversion was calculated via the following equation:

$$
x(t)=\frac{\mathrm{DS}^{(t)}-\mathrm{DS}^{\text {minimal }}}{\mathrm{DS}^{\text {maximum }}-\mathrm{DS}^{\text {minimal }}}
$$

where $x$ is the fractional conversion, $\mathrm{DS}^{(t)}$ is the dry solid content determined at time $t$ of the reaction, DS ${ }^{\text {minimel }}$ is the dry solid content at the start of the reaction, and DS ${ }^{\text {maximum }}$ dry solid content at $100 \%$ conversion, both the last parameters being calculated from the recipe. Conversions assessed in this way were accurate to within $0.5 \%$. Even though the gas cap is minimized a limited percentage of the butadiene is present as the gas phase in the reactor. This caused a small systematic error for gravimetrical conversion data; however, this error is of negligible importance compared to statistical errors involved in the sampling. Nevertheless, excessive sampling was avoided. Final conversions were measured by four gravimetrical samples, all usually within $1 \%$ conversion. Recipes were weighed to within a $0.01-g$ accuracy, reducing recipe errors on the total reactor volume of $1180 \mathrm{~cm}^{3}$ to negligible values. The densitometric technique seems well suited and accurate for this system, even when considering that a hot heterogeneous mixture of water and a monomer-swollen polymer with a low glass transition temperature of $-86^{\circ} \mathrm{C}$ at a pressure of $7 \mathrm{bar}$ is pumped through a glass cell. Filtering of the raw density data was found to be unnecessary. The conversion calibration of the density data is always an interpolation between gravimetrical data, never an extrapolation. The conversion data are transformed into plots of $-\ln (1-x)$ versus time. The slope of the linear part of these plots is determined by linear regression. Generally some 1000 data points are used to create the $-\ln (1-$ $x$ ) versus time plots.

The degree of network formation in the seed latex particles is restricted to moderate levels by the use of tert-dodecylmercaptan, and therefore the swelling of the polymer with monomer was not significantly affected. This finding is in agreement with literature data. 14,15,20 The steady-state slopes of plots such as Figure 3 indicate that the effect of network formation formed during the seeded polymerizations was not significant enough to disturb the steady-state polymerization rate. The recipe is designed to start the polymerizations at the beginning of interval III. The weight fraction of polymer at which the polymerization system goes from interval II to interval III is determined on the basis of kinetic measurements by Weerts et al. ${ }^{15,21}$ and found to be 0.6 over a wide range of experimental conditions. The start of interval III depends on the saturation monomer solubility in the polymer $\left(C_{\mathrm{m}}\right.$ in interval II): Bhakuni14 and Weerts et al. 15,21 reported that $C_{\mathrm{m}}$ is unaffected by moderate network formation in the polymer particles and independent of particle size for the range utilized in this work. The degree of network formation in the polymer particles was characterized by the gel content. The gel content was measured with a toluene extraction method 16,20 and is based on the extraction of the soluble fraction of the polybutadiene. The insoluble residue is by definition the gel fraction. The polybutadiene is isolated from the latex by precipitation, washed, and dried. An accurately weighed $1-\mathrm{g}$ sample is dissolved in $100 \mathrm{~mL}$ of toluene and moderately agitated for $48 \mathrm{~h}$. The solution is filtered, and $50 \mathrm{~mL}$ of filtrate is evaporated until constant weight. The gel content is calculated according to

$$
\text { gel content }=\left(w_{\mathrm{PB}}-2 w_{\mathrm{F}}\right) / w_{\mathrm{PB}}
$$

where $w_{\mathrm{PB}}$ is the weight of the $\mathrm{PB}$ sample and $w_{\mathrm{F}}$ is the weight of the dried filtrate. The factor 2 in eq 2 originates from the fact that $100 \mathrm{~mL}$ is used for extraction and only $50 \mathrm{~mL}$ of the filtrate is used.

The density of polybutadiene at $60^{\circ} \mathrm{C}$ was measured in the form of a latex using a Anton Paar DMA 55 internal density cell, 
Table II

Gel Content and Density of the Polymer PPB of Seed Lateres with a Range of Weight-Average Particle Diameters $d_{w}$ and Polydiapereity $P$

\begin{tabular}{cccc}
\hline$d_{\mathrm{w}}(\mathrm{nm})$ & $P$ & gel content $(\%)$ & $\rho_{\mathrm{PB}}\left(\mathrm{kg} \mathrm{m}^{-3}\right)$ \\
\hline 235 & 1.007 & 51.0 & 860 \\
207 & 1.010 & 76.1 & 860 \\
216 & 1.014 & 49.3 & 858 \\
190 & 1.020 & 69.1 & 861
\end{tabular}

combined with the determination of the solid content of the latex, and found to be $860 \mathrm{~kg} \mathrm{~m}^{-3}$, independent of particle size and gel content (see Table II). This is an important result since the density of polybutadiene at the reaction temperature is used to calculate the monomer concentration in the particles.

Latex Particle Characterization. The average particle diameter and the particle size distribution were measured using transmission electron microscopy (TEM; Jeol $2000 \mathrm{FX}$ ) in combination with $\mathrm{O}_{8} \mathrm{O}_{4}$ staining techniques. Typically some 1000 particles were counted (Zeiss TGA-10 particle analyzer) on a micrograph taken from various parts of the TEM sample grid. Calibration of the measured particle diameters was performed with a specimen of known diameter. The particle diameters mentioned in this paper are weight-average diameters $d_{w}$ and number-average particle diameters $d_{n}$. Particle size distributions of the seed latexes used were extremely narrow (typically polydispersity \pm 1.01 ). Polydispersity $(P)$ is defined as $d_{w} / d_{n}$. The number concentration of particles, $N$, is calculated from

$$
N=\frac{6(\mathrm{M} / \mathrm{W}) \rho_{\mathrm{w}}}{\pi \rho_{\mathrm{PB}} d_{\mathrm{w}}{ }^{3}}
$$

where $(M / W)$ is the monomer to water weight ratio, $\rho_{w}$ the density of water at $60^{\circ} \mathrm{C}$, and $\rho_{\mathrm{PB}}$ the density of polybutadiene at $60^{\circ} \mathrm{C}$. Special care was undertaken to inspect the particle size distribution of both the seed latex and the final product by TEM for secondary nucleation or coagulation, neither of which ever occurred during the polymerizations as used here. The monomer concentration in the particles at the start of the polymerization in interval III (a constant) was calculated according to

$$
C_{\mathrm{m} 0}=\frac{\frac{M^{\text {but }}}{\mathrm{MW}^{\text {but }}}}{\frac{M^{\text {but }}}{\rho_{\text {but }}}+\frac{M^{\mathrm{PB}}}{\rho_{\mathrm{PB}}}}
$$

where $M^{\text {but }}$ is the initial mass of butadiene utilized (see Table I), $M W^{\text {but }}$ is the molecular weight of butadiene, $\rho_{\text {but }}$ is the density of butadiene at $60^{\circ} \mathrm{C}$, and $M^{\mathrm{PB}}$ is the initial mass of polybutadiene utilized. The slight volume contraction occurring when mixing polybutadiene and butadiene is not compensated for, causing a small systematic error in $C_{m 0}$.

\section{Theory}

Seeded emulsion polymerizations were performed in the Smith-Ewart interval III regime. An interval III analysis is relatively straightforward: the monomer concentration in the particles is described by ${ }^{27}$

$$
\frac{-\mathrm{d} \ln (1-x)}{\mathrm{d} t}=\frac{k_{\mathrm{p}} n C_{\mathrm{m} 0} N}{N_{\mathrm{av}} n_{\mathrm{m} 0}}
$$

where $k_{\mathrm{p}}$ is the propagation rate coefficient, $n$ is the average number of radicals per particle, $N_{\mathrm{av}}$ is Avogadro's constant, and $n_{\mathrm{m} 0}$ is the number of moles of monomer present per unit volume of the water phase at the beginning of interval III (a constant). From the steady-state regime of a plot of $-\ln (1-x)$ versus time the product of $k_{p} n$ can be calculated since all other variables on the right-hand side of eq 5 are known (e.g., Figure 3). Note that a value for $k_{\mathrm{p}}$ cannot be calculated from such a plot until the value of $n$ is known. For this reason several important results deduced ${ }^{15,21}$ from ab initio interval II and III analyses of

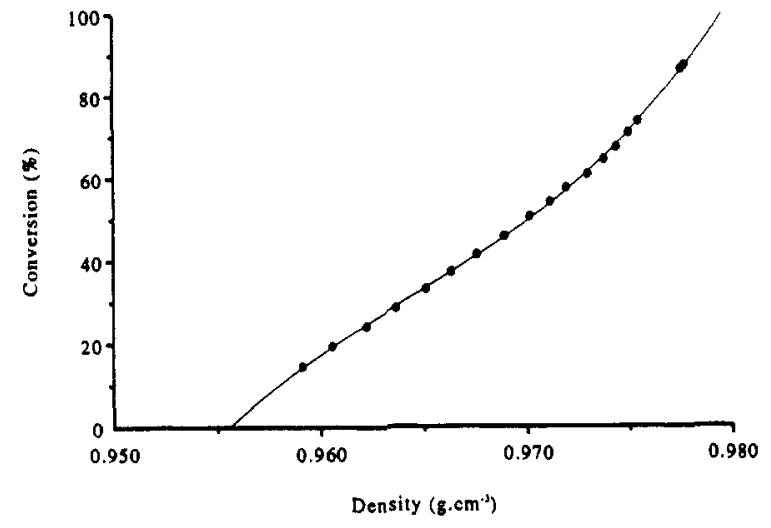

Figure 1. Calibration of density date $\left(\mathrm{g} \mathrm{cm}^{-3}\right)$ with gravimetrical conversion data $(\%)$ of corresponding reaction times.

the emulsion polymerization of butadiene need to be evaluated. From ab initio interval II analysis it was shown that the polymerization kinetics depend solely on particle size: there is a decrease in the rate per particle with decreasing particle size. Using the estimate for the value of $k_{\mathrm{p}}$ of $100 \mathrm{~L} \mathrm{~mol}^{-1} \mathrm{~s}^{-1}$ reported by Morton et al. ${ }^{8}$ implies that $n \ll 0.5$. Ab initio interval III analysis ${ }^{16,21}$ showed that plots $-\ln (1-x)$ versus time under various initiator and electrolyte concentrations and over a wide range of particle sizes are linear. However, bimolecular termination rate coefficients are expected to vary significantly with the weight fraction of polymer $\left(w_{p}\right)$ in interval III. Therefore, the following conclusions were reached:

1. Termination is not rate determining and thus instantaneous upon entry of free radicals into particles. This leads to the conclusion that butadiene is a SmithEwart case I or II system at $62^{\circ} \mathrm{C}$ and at particle diameters below $200 \mathrm{~nm}$. This is an important consideration, since in the limit of $n=0.5$ a value for $k_{\mathrm{p}}$ can be calculated from the steady-state regime of the plot of $-\ln (1-x)$ versus time and the rate eq 5 .

2. Both $n$ and $k_{p}$ are constant during a particular polymerization up to $w_{\mathrm{p}}=0.85$, since it is highly unlikely that $\hbar$ and $k_{\mathrm{p}}$ would counterbalance each other under the wide range of experimental conditions. This is because the right-hand side of eq 5 consists of only constants within a particular polymerization. Thus for every separate seeded polymerization a unique value of the product of $k_{\mathrm{p}} n$ can be determined.

The aim of this work was to see if raising the particle diameter above $200 \mathrm{~nm}$ in seeded polymerizations could drive $n$ to the limiting Smith-Ewart case II value of $n=$ 0.5 . This would enable the calculation of $k_{\mathrm{p}}$ at that limit. This strategy is slightly different from the one that has been successfully applied to the styrene system. ${ }^{1,28}$ Here the initiator concentration was increased to raise $n$. In the butadiene case particle diameter is increased since it has been reported that the polymerization rate per particle in the butadiene case in insensitive to large changes in initiator concentration. ${ }^{5,16-18,21,29}$

\section{Results and Discussion}

To convert the gravimetrical conversion data and density data in to conversion-time data, three plots were made for every polymerization (each polymerization was separately calibrated). Examples of such plots are depicted in Figures $1-3$. In Figure 4 a plot of $k_{p} n$, calculated from eq 5 and with the use of slopes from curves for reactions with varying particle diameters, as in Figure 3, is presented. The data clearly show that $n$ is constant above particle sizes of 200 $\mathrm{nm}$, strongly suggesting that this corresponds to $n=0.5$. Below particle diameters of $200 \mathrm{~nm}$ the approach to the 


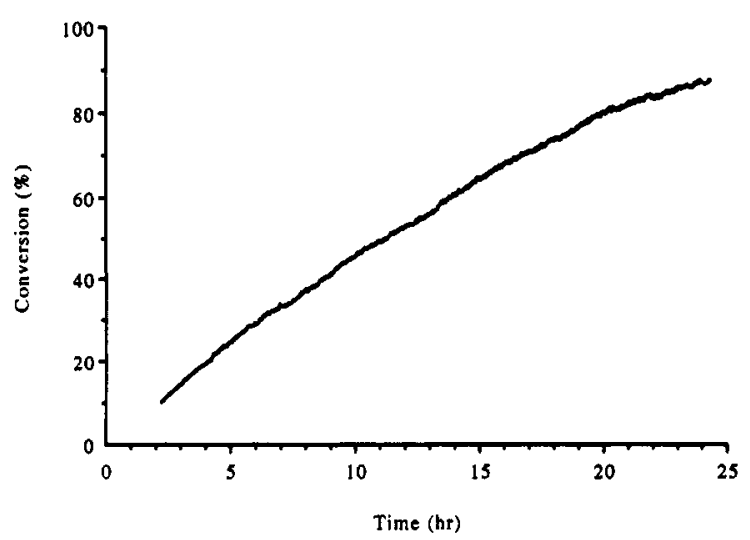

Figure 2. Conversion in interval III (\%) versus reaction time (h). These plots consist of an average of 1000 data points gained from transforming density data into conversion data.

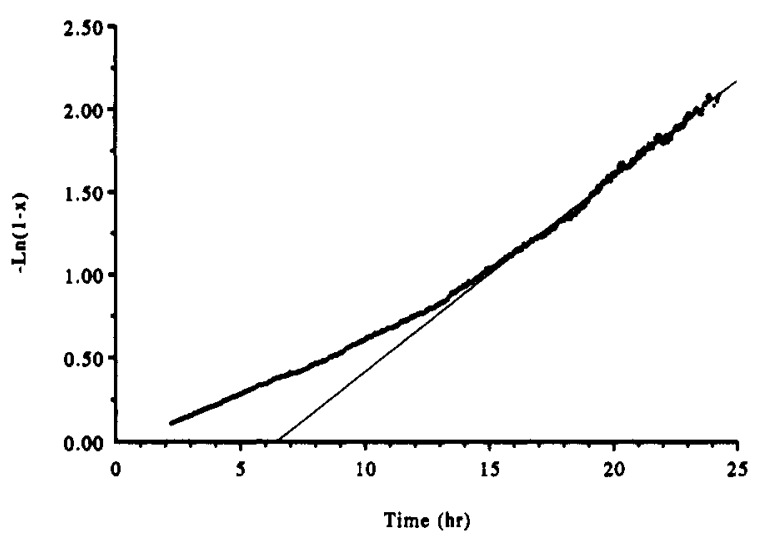

Figure 3. $-\ln (1-x)$ versus reaction time (h) calculated from conversion-time data depicted in Figure 2. The plot shows an approach to steady state and a steady-state linear part. The slope of the linear part of such plots is used in eq 5 to calculate the product of the propagation rate coefficient, $k_{\mathrm{p}}\left(\mathrm{L} \mathrm{mol}^{-1} \mathrm{~s}^{-1}\right)$, and the average number of radicals per particle, $n$.

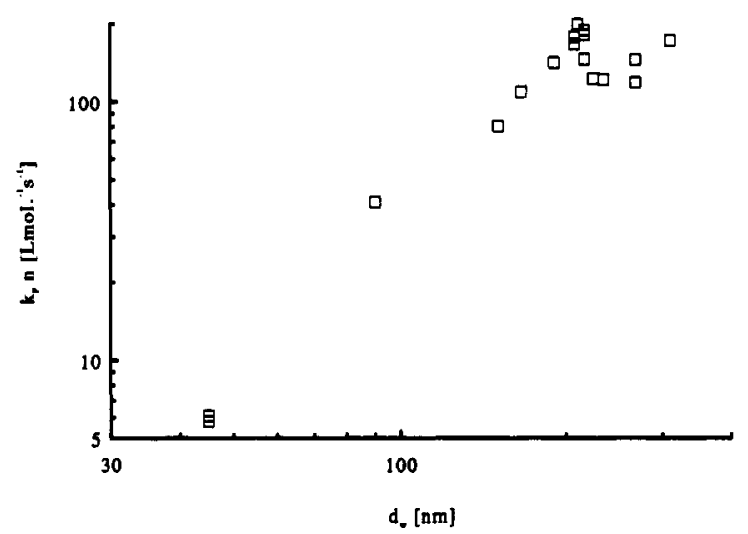

Figure 4. Product of the propagation rate coefficient, $k_{\mathrm{p}}(\mathrm{L}$ $\mathrm{mol}^{-1} \mathrm{~g}^{-1}$ ) and the average number of radicals per particle, $n$, versus seed latex particle diameter (nm). The plot shows a plateau for particle diameters $>200 \mathrm{~nm}$ and an approach to that plateau for particle diameters $<200 \mathrm{~nm}$.

limit of $n=0.5$ is apparent and in excellent agreement with the data reported by Weerts et al. 15,21 Table III incorporates the values necessary to calculate the experimental values of $k_{\mathrm{p}} n$.

For the experiments performed the particle concentration is varied over 2 orders of magnitude while $C_{\mathrm{m} 0}$ and $n_{\mathrm{m} 0}$ are virtually constant. Note that the $C_{\mathrm{m} 0}$ never surpasses the maximum reported ${ }^{15,21}$ solubility of butadiene in polybutadiene of $C_{\mathrm{m}}=5.6 \mathrm{~mol} \mathrm{~L}^{-1}$; hence, all polymerizations are performed in interval III. The constant value of $n$ above particle diameters of $200 \mathrm{~nm}$ shows some scatter due to a combination of inaccuracies inherent
Table III

Values Calculated from Experiments Performed on Seed Latexes of Weight-Average Diameter $d_{w}$, for the Number Concentration of Particles $\boldsymbol{N}$, Monomer Concentration in the Particle at the Start of the Polymerization $C_{\text {mos }}$ Number of Moles of Monomer Present per Unit Volume of Aqueous Phase $n_{m 0}$, Slope of the Linear Part of the Plots $-\ln (1-x)$ versus Time, and the Product of the Propagation Rate Coefficient $\boldsymbol{k}_{\mathrm{p}}$ and the Average Number of Radicals per Particle a

\begin{tabular}{rccccc}
\hline $\begin{array}{c}d_{\mathrm{w}} \\
(\mathrm{nm})\end{array}$ & $\begin{array}{c}N_{\mathrm{w}} \times 10^{-19} \\
\left(\mathrm{~m}^{-3}\right)\end{array}$ & $\begin{array}{c}C_{\mathrm{m} 0} \times 10^{-3} \\
\left(\mathrm{~mol} \mathrm{~m}^{-3}\right)\end{array}$ & $\begin{array}{c}n_{\mathrm{m0}} \times 10^{-3} \\
\left(\mathrm{~mol} \mathrm{~m}^{-3}\right)\end{array}$ & $\begin{array}{c}\text { slope } \\
\left(\mathrm{h}^{-1}\right)\end{array}$ & $\begin{array}{c}k_{\mathrm{p}} n \\
\left(\mathrm{~L} \mathrm{~mol}^{-1} \mathrm{~s}^{-1}\right)\end{array}$ \\
\hline 310 & 0.79 & 5.39 & 1.408 & 0.0311 & 171.2 \\
268 & 1.05 & 5.34 & 1.390 & 0.0392 & 162.3 \\
268 & 1.22 & 5.26 & 1.338 & 0.0340 & 118.0 \\
268 & 1.22 & 5.28 & 1.348 & 0.415 & 144.4 \\
234 & 1.98 & 5.30 & 1.361 & 0.0558 & 121.4 \\
224 & 2.09 & 5.29 & 1.353 & 0.0599 & 122.4 \\
216 & 2.30 & 5.28 & 1.351 & 0.0781 & 145.3 \\
216 & 2.34 & 5.33 & 1.373 & 0.0983 & 180.4 \\
216 & 2.34 & 5.31 & 1.362 & 0.1027 & 187.8 \\
210 & 2.55 & 5.34 & 1.380 & 0.1171 & 198.1 \\
207 & 2.64 & 5.28 & 1.348 & 0.1098 & 177.2 \\
207 & 2.64 & 5.50 & 1.468 & 0.0985 & 166.1 \\
190 & 3.42 & 5.13 & 1.396 & 0.1062 & 141.2 \\
166 & 5.17 & 5.40 & 1.418 & 0.1289 & 109.1 \\
151 & 6.82 & 5.32 & 1.368 & 0.1277 & 80.3 \\
90 & 31.8 & 5.28 & 1.350 & 0.3055 & 40.9 \\
45 & 264 & 5.33 & 1.371 & 0.3550 & 5.8 \\
45 & 275 & 5.31 & 1.365 & 0.3888 & 6.1
\end{tabular}

Table IV

Seed Latex Particle Diameter $d_{w}$, Number Concentration of Particles N, Slope of the Linear Part of the Plote -ln $(1-x)$ versus Time, and the Product of the Propagation Rate Coefficient $b_{p}$ and the Average Number of Radicals per Particle $n$ of Two Experiments, One of Which Was Pre-heat-treated To Inspect Any Effect of "Thermal Background Initiation"

\begin{tabular}{ccc}
\hline$d_{\mathrm{w}}(\mathrm{nm})$ & $N \times 10^{-19}\left(\mathrm{~m}^{-3}\right)$ & $k_{\mathrm{p}} n\left(\mathrm{~L} \mathrm{~mol}^{-1} \mathrm{~B}^{-1}\right)$ \\
\hline 216 & 2.34 & 180.4 \\
$216^{a}$ & 2.34 & 187.8
\end{tabular}

a Pre-heat-treated seed later.

in determining the slopes of $-\ln (1-x)$ versus time curves (ca. $10 \%$ ) and also in the latex particle concentrations (ca. $10 \%)$. The propagation rate coefficient can consequently only be calculated with limited accuracy, as is expected from such a model-dependent method. The value for the propagation rate coefficient determined from Figure 4 is $k_{\mathrm{p}}=320 \pm 50 \mathrm{~L} \mathrm{~mol}^{-1} \mathrm{~s}^{-1}$. Note however that this new value is 3 times higher than the value reported by Morton et al..$^{8}$ No model-independent value of the propagation rate coefficient is known for butadiene.

It is worthwhile noting that "background initiation"30 of origin, other than added persulfate, may fluctuate with, say, seed latex size and could be a cause of the scatter mentioned in the previous paragraph. The possible presence of a "thermal background initiation" rate in the butadiene system was checked by performing two seeded polymerizations on the same seed latex. In one of the experiments the seed latex was covered with $75 \%$ of the maximum SDS coverage (as was determined by tensiometric titration) and heated at $80^{\circ} \mathrm{C}$ for $16 \mathrm{~h}$ before swelling and polymerization. The other experiment was performed normally. The heating of the latex will hopefully decompose any radical, yielding substances like peroxides of residual persulfate. Table IV shows the results of both polymerizations. No significant difference in slopes or $n$ is found, even though the particle diameter used is in the case II range were an effect of thermal background initiation on $\rho$ should show up in the rate of polymerization. Therefore it was concluded that thermal background 
Table V

Numeric Values of the Parameters and Recipe Information Used in the Model Calculations

\begin{tabular}{clll}
\hline parameter & \multicolumn{1}{c}{ value } & parameter & \multicolumn{1}{c}{ value } \\
\hline$k_{\mathrm{d}}$ & $6.3 \times 10^{-6} \mathrm{~g}^{-1}$ & $k_{\mathrm{p} 0}$ & $\approx k_{\mathrm{p}} \mathrm{L} \mathrm{mol}^{-1} \mathrm{~s}^{-1}$ \\
$k_{\mathrm{t}}$ & $7 \times 10^{9} \mathrm{~L} \mathrm{~mol}^{-1} \mathrm{~s}^{-1}$ & {$[1]$} & $10^{-2} \mathrm{~mol} \mathrm{~L}^{-1}$ \\
$z$ & 3 & $M^{\text {but a }}$ & $65 \mathrm{~g}$ \\
$k_{\mathrm{p}}$ & $320 \mathrm{~L} \mathrm{~mol}^{-1} \mathrm{~g}^{-1}$ & $M^{\mathrm{PB} \mathrm{a}}$ & $97.5 \mathrm{~g}$ \\
$M_{\mathrm{aq}}$ & $37 \times 10^{-3} \mathrm{~mol} \mathrm{~L}^{-1}$ & $M^{\mathrm{w} a}$ & $877.5 \mathrm{~g}$ \\
$D^{\prime \prime}$ & $1.5 \times 10^{-7} \mathrm{dm}^{2} \mathrm{~s}^{-1}$ & $\rho_{\mathrm{PB}}{ }^{b}$ & $0.86 \mathrm{~g} \mathrm{~cm}^{-3}$ \\
$q$ & 151 & $\rho_{\mathrm{but}}{ }^{b}$ & $0.57 \mathrm{~g} \mathrm{~cm}^{-3}$ \\
$k_{\mathrm{tr}}$ & $0.1-0.01 \mathrm{~L} \mathrm{~mol}^{-1} \mathrm{~s}^{-1}$ & $\rho_{\mathrm{w}}{ }^{b}$ & $0.98 \mathrm{~g} \mathrm{~cm}^{-3}$
\end{tabular}

a The amounts added in the recipe as depicted in Table I. ${ }^{b}$ The density values at $60^{\circ} \mathrm{C}$ are used.

initiation was a negligible effect in the butadiene system and not the cause of the previously mentioned scatter in slopes or $\bar{n}$. This however does not exclude other forms of background initiation: further work is being done on this subject. ${ }^{31}$

From Figure 3 it is obvious that the butadiene system has a relatively long (up to $15 \mathrm{~h}$ is observed) semilinear region before it reaches a final and steepest linear region. Note that this is not necessarily a kinetically determined approach to steady state. However, the butadiene system does show behavior similar to the conduct of butyl acrylate ${ }^{32}$ or styren $e^{30}$ where a kinetically determined and relatively short (on the order of minutes) approach to steady state is common. ${ }^{31}$ From this final linear region the slope was used to calculate the $\bar{n}$ values. This is important in determining the plateau region in Figure 4, since it means that the $n$ values calculated are the maximum values to occur during the polymerizations. The reason for this unusual result is not yet clear. Note that should retardation be present, this stops when a steady state is reached and therefore has no effect on the value of the steady-state slope or $n$. This point illustrates the importance of accurate and frequent data collection: the first linear region in Figure 3 could easily be mistaken for a final steady state leading to too low values of $n$. A serious disadvantage of the experimental data is that, because of the two regions' behavior, no entry or exit rate coefficients can be calculated, utilizing the slope and intercept method described by Gilbert et al. ${ }^{27}$ More work is being done on this subject and will be published separately. ${ }^{31}$

\section{Model Calculations}

In this section known theories for entry and exit of radicals from latex particles are combined in a model to elucidate the behavior of the average radical concentration in the particles of an emulsion polymerization of butadiene as a function of particle diameter.

The increase of $n$ with increasing particle size is due to two phenomena: the increase of the entry rate caused by a decrease of the particle concentration in the various recipes and a simultaneous decrease of the exit rate because of an increase in the particle diameter.

1. The entry rate coefficient for radicals into particles ( $\rho$ ) as reported by Maxwell et al. ${ }^{33,34}$ is given by eq 6:

$$
\rho=\left[\frac{2 k_{\mathrm{d}}[\mathrm{I}] N_{\mathrm{av}}}{N}\right]\left[\frac{2 k_{\mathrm{t}}\left[\mathrm{T}^{*}\right]}{k_{\mathrm{p}} M_{\mathrm{aq}}}+1\right]^{1-\mathrm{z}}
$$

where $\rho$ is the entry rate coefficient, $k_{\mathrm{d}}$ is the dissociation rate coefficient of peroxodisulfate, [I] is the initiator concentration, $k_{\mathrm{t}}$ is the bimolecular termination rate coefficient of two radicals in the water phase, [T*] is the total aqueous phase radical concentration for which Ugelstad et al. ${ }^{35}$ used $\left[\mathrm{T}^{*}\right] \approx\left(k_{\mathrm{d}}[\mathrm{I}] / k_{\mathrm{t}}\right)^{1 / 2}, M_{\mathrm{sq}}$ is the

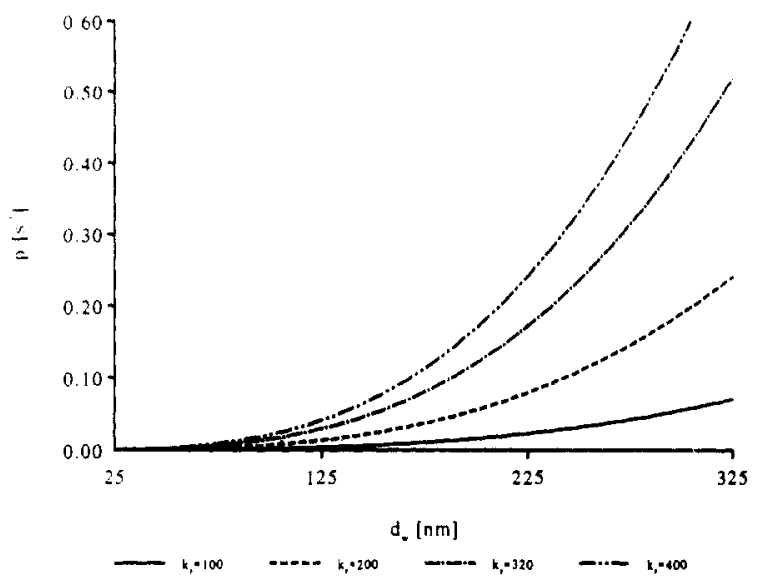

Figure 5. Model calculation according to of 6 of entry rate coefficient $\rho\left(\mathrm{g}^{-1}\right)$ for various values of the propagation rate coefficient, $k_{\mathrm{p}}\left(\mathrm{L} \mathrm{mol}^{-1} \mathrm{~s}^{-1}\right)$.

butadiene water solubility, and $z$ is the degree of polymerization that causes an oligomeric radical with a sulfate end group to be surface active. The values of the parameters are listed in Table V. The following brief discussion presents some information about the parameters used. The value for $k_{\mathrm{d}}$ used is reported in the literature and measured in the presence of butadiene in an emulsion system: $6.3 \times 10^{-6} \mathrm{~s}^{-1} .15,36$ From the literature it is known that bimolecular termination rate constants $\left(k_{t}\right)$ in aqueous media are on the order of magnitude of $10^{9}-10^{10} \mathrm{~L} \mathrm{~mol}^{-1} \mathrm{~s}^{-1} \cdot 34,37-40$ For $M_{\mathrm{aq}}$ the value of $37 \times 10^{-3}$ mol L $\mathrm{L}^{-1} 41$. is taken since this value is measured at a saturation pressure of butadiene, comparable with polymerization conditions. The value for $z$ used is 3 monomer units, calculated from a method described by Maxwell et $a^{3}{ }^{33}$ Further work is being done on this value.29 The entry rate coefficient, $\rho$, is inversely proportional to the number of particles present in the water phase. In the recipes used the amount of polymer is chosen to be constant; accordingly, the number of particles decreases with the particle diameter. Hence, $\rho$ increases as the particle size increases. In Figure 5 the entry rate coefficient calculated according to eq 6 is depicted versus particle diameter for various values of the propagation rate coefficient. One of the curves in Figure 5 should reflect the actual entry rate coefficients of the experimental polymerizations since at each particle size the experimental particle number concentration was used to calculate the entry rate coefficient. It is apparent that the predicted entry rate coefficient increases rapidly over the experimental range of particle number concentrations.

2. The first-order exit rate coefficient is given by ${ }^{42}$

$$
k=k_{\mathrm{tr}} C_{\mathrm{m}}\left[\frac{k_{\mathrm{es}}}{k_{\mathrm{es}}+k_{\mathrm{p} 0} C_{\mathrm{m}}}\right]
$$

where $k_{t r}$ is the rate coefficient for transfer to monomer, $k_{\mathrm{p} 0}$ is the propagation rate coefficient of a single monomeric radical with a monomer unit, and $k_{e s}$ is the escape rate coefficient of monomer from the particle given by

$$
k_{\text {et }}=3 D^{\prime \prime} / R_{\mathrm{s}}{ }^{2} q
$$

where $R_{\mathrm{s}}$ is the swollen radius of the later particles, $q$ is the partition coefficient of the monomeric radicals between the particle and water phases $\left(q=C_{m} / M_{2 q}\right)$, and $D^{\prime \prime}$ is the diffusion coefficient of the monomeric radical in water. $D^{\prime \prime}$ is calculated according to the Wilke and Changts equation and found to be $1.5 \times 10^{-7} \mathrm{dm}^{2} / \mathrm{s}$. 


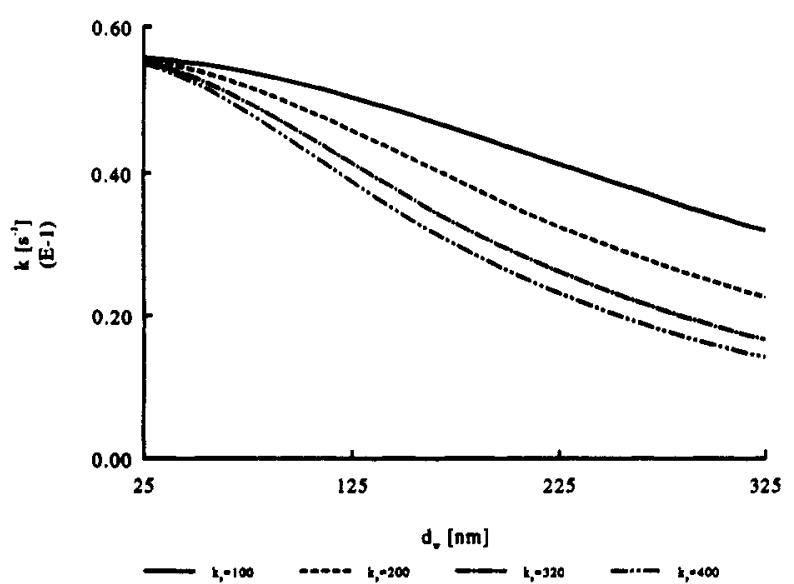

Figure 6. Model calculation according to eq 9 of exit rate coefficient $k(\mathrm{~s})$, with the use of the swollen diameter, versus particle diameter, $d_{w}(n m)$.

Introducing the expression for the first-order rate coefficient for escape in the final equation for the exit rate coefficient as proposed by Ugelstad and Hansen renders

$$
k=k_{\mathrm{tr}} C_{\mathrm{m}}\left[\frac{\frac{3 D^{\prime \prime}}{\left(1 / 2 d_{\mathrm{m}}\right)^{2} q}}{k_{\mathrm{p} 0} C_{\mathrm{m}}+\frac{3 D^{\prime \prime}}{\left(1 / 2 d_{\mathrm{wg}}\right)^{2} q}}\right]
$$

Very little is reported on the value for $k_{\mathrm{tr}}$ except for a estimation on kinetic grounds by Weerts et al. ${ }^{15,21}$ of $k_{\mathrm{tr}}$ $=0.1 \mathrm{~L} \mathrm{~mol}^{-1} \mathrm{~g}^{-1}$. The monomer concentration in the particles, $C_{\mathrm{m}}$, is reported 16,21 to be $5.6 \mathrm{~mol} \mathrm{~L}^{-1}$. The value of $k_{\mathrm{p} 0}$ may differ from the long-chain value of $k_{\mathrm{p} ;}{ }^{42}$ however, for simplicity in the following discussion $k_{\mathrm{po}}$ is assumed to be identical to $k_{\mathrm{p}} . d_{\mathrm{w}}$ is the swollen weight-average particle diameter. Figure 6 shows the values of the exit rate coefficient predicted from eq 9 for various values of $k_{\mathrm{p} 0}$ (actually $k_{\mathrm{p}}$ ). It is apparent that the exit rate coefficients decrease with particle diameter although the decrease is less significant than the increase in entry rate coefficients. One of the curves in Figure 6 should reflect the actual exit rate coefficient of the experimental polymerizations, since at each particle size the experimental particle concentration was used to calculate the exit rate coefficient by eq 9 .

Assuming that the Smith-Ewart case I and II approximations hold for the butadiene polymerization system at interest, $n$ can be calculated in terms of the entry and exit rate coefficients. 4

$$
n=\rho /(2 \rho+k)
$$

It is easily shown that as the particle diameter increases the corresponding increase in $\rho$ and decrease in $k$ results in the limiting value of $n=0.5$. In practice this means that a plot of $k_{p} n$ versus particle diameter, in analogy with the well-known Ugelstad graphs, ${ }^{45}$ should show a constant value of $k_{\mathrm{p}} n$ (in fact a constant value of $n$ since $k_{\mathrm{p}}$ is assumed to be constant) above a certain particle diameter as long as the Smith-Ewart case II approximation holds. Figure 7 shows a graph of $k_{\mathrm{p}} n$ versus particle diameter calculated with the use of the values for the calculated entry rate coefficient, $\rho$, and exit rate coefficient, $k$, of Figures 5 and 6. Comparison of the experimental data ( $n$ versus $d_{w}$ ) with the model prediction (Figure 7) indicates that the model predicts both the approach to the plateau and the existence of the plateau itself. Note that the $k_{\mathrm{p}}$ is varied over a small range compared to the usual inaccuracy in which propagation rate coefficients are known. The curve

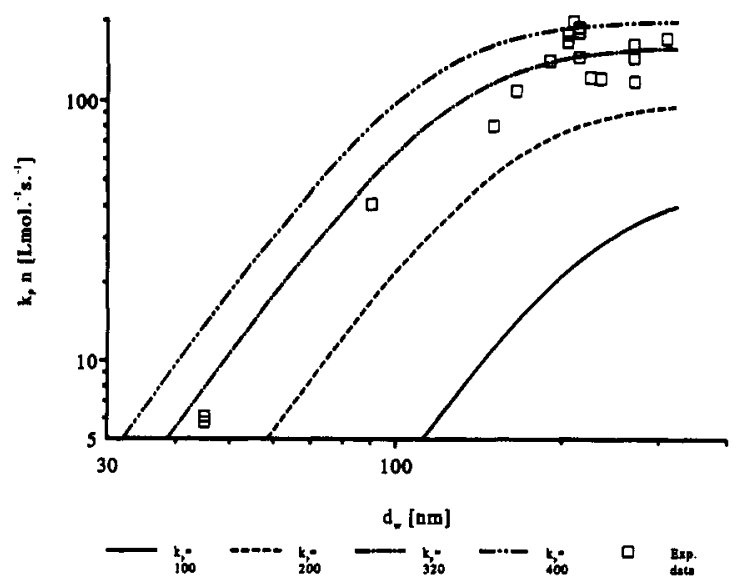

Figure 7. Model calculations and experimental data of the products of the propagation rate coefficient, $k_{\mathrm{p}}\left(\mathrm{L} \mathrm{mol}^{-1} \mathrm{~g}^{-1}\right)$, and the average number of radicals per particle, $n$, versus seed latex particle diameter $(\mathrm{nm})$.

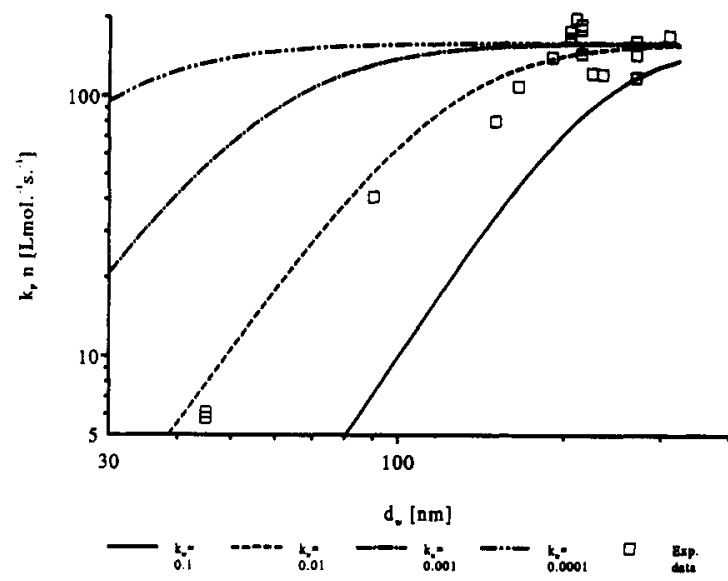

Figure 8. Model calculations and experimental data of the product of the propagation rate coefficient, $k_{\mathrm{p}}\left(\mathrm{L} \mathrm{mol}^{-1} \mathrm{~s}^{-1}\right)$, and the average number of radicals per particle, $n$ versus seed latex particle diameter $d_{w}$ for $k_{\mathrm{p}}=320 \mathrm{~L} \mathrm{~mol}^{-1} \mathrm{~s}^{-1}$, the bimolecular termination rate coefficient $k_{\mathrm{t}}=7 \times 10^{9} \mathrm{~L} \mathrm{~mol}^{-1} \mathrm{~s}^{-1}$, and various values of the rate coefficient for transfer of radical activity to monomer, $k_{\mathrm{tz}}\left(\mathrm{L} \mathrm{mol}^{-1} \mathrm{~s}^{-1}\right)$.

describing the experimental data includes two pieces of independent information:

1. The data show a plateau in $n$ versus $d_{w}$ from which a propagation rate coefficient can be determined. The assumptions necessary to reach this conclusion are as follows: (a) butadiene behaves like a Smith-Ewart case I or II system; (b) $k_{\mathrm{p}}$ and $n$ are both constant throughout interval III; (c) $n=0.5$ at the plateau value (case II approximation).

2. An approach to a plateau is expected as a consequence of the shift from case I to case II kinetics. It will be shown below that, given a value of the $k_{\mathrm{p}}$ determined by the plateau regime, a value of $k_{\mathrm{tr}}$ can be deduced from the nonplateau regime of the $k_{\mathrm{p}} h$ versus $d_{\mathrm{w}}$ plot.

The fact that both regimes discussed above can be fitted using the Smith-Ewart case II approximations (eq 10) and models for $\rho$ and $k$ is a strong indication that the use of these approximations for the butadiene system is justified.

The fit of model and experiment is extremely sensitive to variations in the values of $k_{t r}$ and $k_{t}$. Figure 8 shows a plot of calculated $k_{\mathrm{p}} n$ values versus particle diameter using $k_{\mathrm{p}}=320 \mathrm{~L} \mathrm{~mol}^{-1} \mathrm{~s}^{-1}$ for various values of $k_{\mathrm{tr}}$. Note that the $k_{t r}$ is varied over a wide range. The best agreement between model and experiment is for a value of $k_{t r}=0.01$ $\mathrm{L} \mathrm{mol} \mathrm{m}^{-1} \mathrm{~g}^{-1}$. We should note however that these values were found by assuming a value for $k_{\mathrm{t}}=7 \times 10^{9} \mathrm{~L} \mathrm{~mol}^{-1}$ 


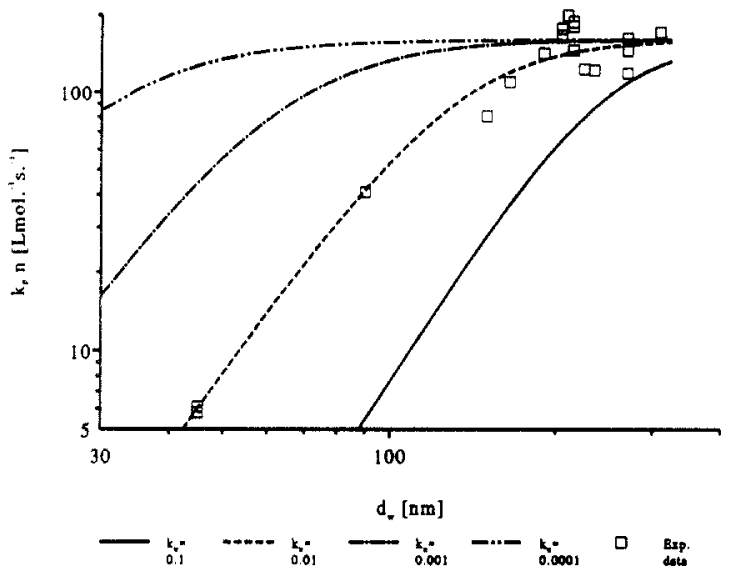

Figure 9. Model calculations and experimental data of the product of the propagation rate coefficient, $k_{\mathrm{p}}\left(\mathrm{L} \mathrm{mol}^{-1} \mathrm{~s}^{-1}\right)$, and the average number of radicals per particle, $n$ versus seed latex particle diameter $d_{w}$ for $k_{\mathrm{p}}=320 \mathrm{~L} \mathrm{~mol}^{-1} \mathrm{~s}^{-1}$, the bimolecular termination rate coefficient $k_{\mathrm{t}}=10^{9} \mathrm{~L} \mathrm{~mol}^{-1} \mathrm{~s}^{-1}$, and various values of the rate coefficient for transfer of radical activity to monomer, $k_{\mathrm{tr}}\left(\mathrm{L} \mathrm{mol} \mathrm{m}^{-1} \mathrm{~s}^{-1}\right)$.

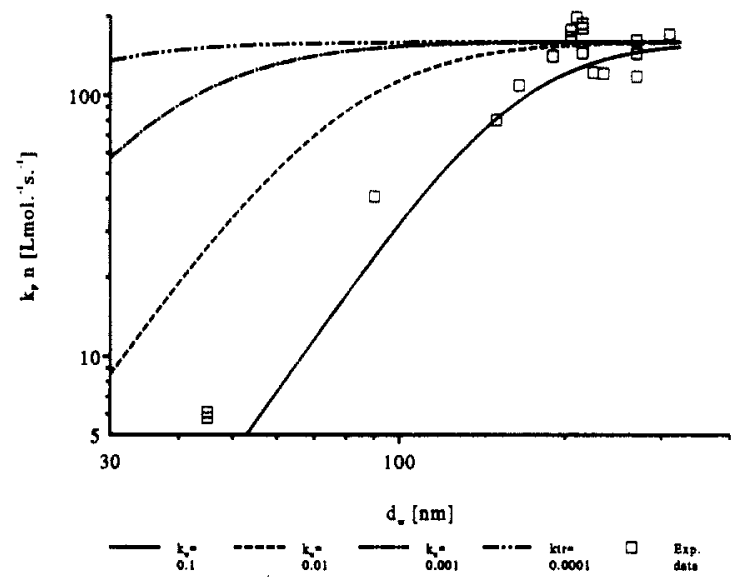

Figure 10. Model calculations and experimental data of the product of the propagation rate coefficient, $k_{\mathrm{p}}\left(\mathrm{L} \mathrm{mol}^{-1} \mathrm{~s}^{-1}\right)$, and the average number of radicals per particle, $h$ versus seed latex particle diameter $d_{\mathrm{w}}$ for $k_{\mathrm{p}}=320 \mathrm{~L} \mathrm{~mol}^{-1} \mathrm{~s}^{-1}$, the bimolecular termination rate coefficient $k_{\mathrm{t}}=10^{10} \mathrm{~L} \mathrm{~mol}^{-1} \mathrm{~s}^{-1}$, and various values of the rate coefficient for transfer of radical activity to monomer, $k_{\mathrm{tr}}\left(\mathrm{L} \mathrm{mol} \mathrm{m} \mathrm{s}^{-1}\right)$.

$\mathrm{s}^{-1}$. Variation of $k_{\mathrm{t}}$ within the range discussed before has a dramatic effect as is shown in Figures 9 and 10. Therefore, $k_{\mathrm{tr}}$ is presented as an order of magnitude value, $k_{\mathrm{tr}}=0.1-0.01 \mathrm{~L} \mathrm{~mol}^{-1} \mathrm{~s}^{-1}$. This range is in accord with the proposed value for the $k_{\mathrm{tr}}$ reported by Weerts et al. ${ }^{15,21}$

From the $k_{\mathrm{p}} n$ versus $d_{\mathrm{w}}$ data the following three conclusions are reached.

1. The propagation rate coefficient can be calculated from the plateau regime. The assumptions necessary to reach this conclusion are as follows: (a) butadiene behaves like a Smith-Ewart case I or II system; (b) $k_{\mathrm{p}}$ and $n$ are both constant during the beginning of interval III; (c) $n$ $=0.5$ at the plateau (case II approximation).

2. The nonplateau regime is a consequence of the shift from case I to case II kinetics and therefore a strong indication of the existence of case I and case II regimes in the butadiene system.

3. The excellent agreement of the model and experiment allows the calculation of an order of magnitude value for $k_{\mathrm{tr}}$ from the nonplateau regime. The fitted value of $k_{\mathrm{tr}}$ is the result of a model calculation using some (in certain limits adjustable) parameters and is therefore only calculated to within an order of magnitude. No value for the $k_{\mathrm{tr}}$ for the butadiene system has been reported except a proposal ${ }^{15,21}$ mentioned earlier.

\section{Conclusions}

The emulsifier free seeded emulsion polymerization of butadiene could be performed at $60^{\circ} \mathrm{C}$ in Smith-Ewart interval III without any coagulation or secondary nucleation. Gravimetrically calibrated densitometry is an extremely useful method for determining monomer conversion at high data acquisition rates with minimal disturbance of the polymerization system.

The density of polybutadiene at $60^{\circ} \mathrm{C}$ was found to be independent of both the particle size and the degree of network formation in the particles (as was determined by the so-called toluene extraction method). The gel content of the seed latexes was moderate and did not affect the monomer solubility in the polymer nor the time needed to swell the polymer.

The plots of $-\ln (1-x)$ versus time show two linear regions. The last and steepest region is used to determine $\bar{n}$. From the data acquired by simultaneously varying the seed latex particle diameter (45-300 nm) and particle number concentration over 2 orders of magnitude, a plot of $k_{\mathrm{p}} \hbar$ versus seed latex particle diameter could be determined. This plot, an analogy to the well-known Ugelstad plots, clearly shows Smith-Ewart case I and case II regimes. From the constancy of $n$ in this plot above a particle diameter of $200 \mathrm{~nm}$, the propagation rate coefficient for butadiene polymerizations at $60^{\circ} \mathrm{C}$ could be estimated to be $320 \pm 50 \mathrm{~L} \mathrm{~mol}^{-1} \mathrm{~s}^{-1}$.

Known theories of emulsion polymerization kinetics are combined into a model that fits the experimental data extremely well and is capable of rendering an extra piece of information in the form of an order of magnitude value for the rate coefficient for transfer of radical activity to monomer. The rate coefficient for transfer to monomer is calculated to be in the range of $0.1-0.01 \mathrm{~L} \mathrm{~mol}^{-1} \mathrm{~s}^{-1}$.

Continuing research is being conducted to clarify the effects upon the emulsion polymerization of butadiene of (a) initiator concentration, ${ }^{29}$ (b) the addition of tertdodecylmercaptan, ${ }^{46}$ and (c) the two regions of linear slope in plots of $-\ln (1-x)$ versus time. ${ }^{31}$ The results of these studies will be published separately.

Acknowledgment. The authors are indebted to DSM Research Geleen, The Netherlands, for financially supporting this work.

\section{References and Notes}

(1) Buback, M.; Garcia-Rubio, L. H.; Gilbert, R. G.; Napper, D. H.; Guillot, J.; Hamielec, A. E.; Hill, D.; O'Driscoll, K. F.; Olaj, O. F.; Shen, J.; Solomon, D.; Moad, G.; Stickler, M.; Tirrell, M.; Winnik, M. A. J. Polym. Sci., Part C: Polym. Lett. 1988, 26, 293.

(2) Olaj, O. F.; Bitai, I.; Gleixner, G.; Makromol. Chem. 1985, 186, 2569 .

(3) Olaj, O. F.; Bitai, I.; Hinkelmann, F. Makromol. Chem. 1987, $188,1689$.

(4) Vervalin, C. H. Hydrocarbon Process. 1990, 3, 23.

(5) Bovey, F. A.; Kolthof, I. M.; Medalia, A. I.; Meohan, E. J. Emulsion Polymerization; Interscience Publishers: New York, 1954.

(6) Morton, M.; Salatiello, P. P. J. Polym. Sci. 1951, 6, 225.

(7) Morton, M.; Salatiello, P. P.; Landfield, H. J. Polym. Sci. 1952, $8,111$.

(8) Morton, M.; Salatiello, P. P.; Landfield, H. J. Polym. Sci. 1952, $8,215$.

(9) Morton, M.; Salatiello, P. P.; Landfield, H. Ind. Eng. Chem. $1952,44,739$.

(10) Wendler, K.; Karim, N.; Fedtke, M. Plaste Kautsch, 1983, 30, 247. 
(11) Wendler, K.; Pielert, L.; Fedtke, M. Plaste Kautsch. 1983, 30, 438.

(12) Wendler, K.; Würtenberg, R.; Fedtke, M. Plaste Kautsch, 1984, $31,367$.

(13) Wendler, K.; Elsner, H.; Hergeth, W. D.; Fedtke, M. Plaste Kautsch. 1985, 32, 128.

(14) Bhakuni, R. S. Ph.D. Thesis, University of Akron, 1964; Chem. Abstr. 1965, 62, 13351b.

(15) Weerts, P. A. Emulsion Polymerization of Butadiene a Kinetic Study. Ph.D. Thesis, Eindhoven University of Technology, Eindhoven, The Netherlands, 1990.

(16) Weerts, P. A.; van der Loos, J. L. M.; German, A. L. Polym. Commun. 1988, 29, 278.

(17) Weerts, P. A.; van der Loos, J. L. M.; German, A. L. Makromol. Chem. 1989, 190, 777.

(18) Weerts, P. A.; van der Loos, J. L. M.; German, A. L. Makromol. Chem. 1990, 191, 2615.

(19) Weerts, P. A.; van der Loos, J. L. M.; German, A. L. Makromol. Chem. 1991, 192, 1993.

(20) Weerte, P. A.; van der Loos, J. L. M.; German, A. L. Makromol. Chem. 1991, 192, 2009.

(21) Weerts, P. A.; German, A. L. Macromolecules 1991, 24, 1622.

(22) Verdurmen, E. M. F. J.; Dohmen, E. H. M.; German, A. L., to be published.

(23) Vanderhoff, J.W.; van den Hul, H. J.; Tausk, R. J. M.; Overbeek, J. Th. G. The Preparation of Monodisperse Latezes with Wellcharacterized Clean Surfaces. In Clean Surfaces: Their Application and Characterization for Interfacial Studies; Goldfinger, G., Ed.; Marcel Dekker, Inc.: New York, 1970.

(24) Ahmed, S. M.; El Alsser, M. S.; Pauli, G. H.; Poehlein, G. W.; Vanderhoff, J. Colloid Interface Sci. 1980, 73 (No. 2), 388.

(25) Schork, F. J.; Ray, W. H. In Emulsion Polymers and Emulsion Polymerization; Bassett, D. R., Hamielec, A. E., Eds.; ACS Symposium Series 165; American Chemical Society: Washington, DC, 1980; p 505 .

(26) Abbey, K. J. In Emulsion Polymers and Emulsion Polymerization, Bassett, D. R., Hamielec, A. E., Eds.; ACS Symposium
Series 165; American Chemical Society: Washington DC, 1981; p 345.

(27) Gilbert, R. G.; Napper, D. H. Polymerizations in Emulsions. In Comprehensive Polymer Science; Eastmond, G. C., Ledwith, A., Russo, S., Sigwalt, P., Vol. Eds.; Allen, G., Bevington, J. C., Eds.; Pergamon: New York, 1989; Vol. 4, Chapter 11, pp 171218.

(28) Napper, D. H.; Gilbert, R. G. J.Macromol. Sci., Rev. Macromol. Chem. 1983, C23, 127.

(29) Verdurmen, E. M. F. J.; Verstegen, J. M. G.; Maxwell, I. A.; German, A. L., to be published.

(30) Hawkett, B. S.; Napper, D. H.; Gilbert, R. G. J. Chem. Soc., Faraday Trans. 1 1980, 76, 1323.

(31) Verdurmen, E. M. F. J.; Gilbert, R. G.; German, A. L., to be published.

(32) Maxwell, I. A.; Napper, D. H.; Gilbert, R. G. J. Chem. Soc., Faraday Trans, 1987, 1 83, 1449.

(33) Maxwell, I. A.; Morrison, B. R.; Napper, D. H.; Gilbert, R. G. Macromolecules 1991, 24, 1629.

(34) Maxwell, I. A. Kinetic Processes in Emulsion Polymerization. Ph.D. Thesis, Sydney University, Sydney, Australia, 1990.

(35) Ugelstad, J.; Hansen, F. K. Emulsion Polymerization. Piirma, I., Ed.; Academic Press: New York, 1982.

(36) Kolthoff, I. M.; Miller, I. K. J. Am. Chem. Soc. 1951, 73, 3055.

(37) Sangster, D. F.; Davison, A. J. Polym. Sci. 1975, 49, 191.

(38) Dainton, F. S.; James, D. G. L. J. Polym. Sci. 1959, 39, 299.

(39) Dainton, F. S.; Eaton, R. S. J. Polym. Sci. 1959, 39, 313.

(40) Fischer, H. Makromol. Chem. 1966, 98, 179.

(41) Reed, C. D.; McKetta, J. J. J. Chem. Eng. Data 1959, 4, 294

(42) Ugelstad, J.; Hansen, F. K. Rubber Chem. Technol. 1976, 49, 536.

(43) Wilke, C. R.; Chang, P. Am. Inst. Chem. Eng. 1955, 1, 264

(44) Smith, W. V.; Ewart, R. H. J. Chem. Phys. 1948, 16, 592.

(45) Ugelstad, J.; Mörk, P. C.; Aasen, J. O. J. Polym. Sci., Polym. Chem. Ed. 1967, 5, 2261.

(46) Verdurmen, E. M. F. J.; Verstegen, J. M. G.; German, A. L., to be published. 